\title{
Interaction of connexin43 and protein kinase C-delta during FGF2 signaling
}

\author{
Corinne Niger, Carla Hebert, Joseph P Stains ${ }^{*}$
}

\begin{abstract}
Background: We have recently demonstrated that modulation of the gap junction protein, connexin43, can affect the response of osteoblasts to fibroblast growth factor 2 in a protein kinase C-delta-dependent manner. Others have shown that the C-terminal tail of connexin43 serves as a docking platform for signaling complexes. It is unknown whether protein kinase C-delta can physically interact with connexin43.

Results: In the present study, we investigate by immunofluorescent co-detection and biochemical examination the interaction between $\mathrm{C} \times 43$ and protein kinase C-delta. We establish that protein kinase C-delta physically interacts with connexin43 during fibroblast growth factor 2 signaling, and that protein kinase $\mathrm{C}$ delta preferentially coprecipitates phosphorylated connexin43. Further, we show by pull down assay that protein kinase C-delta associates with the C-terminal tail of connexin43.

Conclusions: Connexin43 can serve as a direct docking platform for the recruitment of protein kinase C-delta in order to affect fibroblast growth factor 2 signaling in osteoblasts. These data expand the list of signal molecules that assemble on the connexin43 C-terminal tail and provide a critical context to understand how gap junctions modify signal transduction cascades in order to impact cell function.
\end{abstract}

\section{Background}

Gap junctions are transcellular channels formed by the juxtaposition of two hemichannels, each composed of six connexin monomers, present on adjacent cells. The assembled gap junctions then aggregate to form gap junction plaques. Gap junctional communication maintains metabolic continuity between cells and mediates the rapid and efficient transmission of small molecules, including second messengers among the interconnected cells.

Connexin43 (Cx43) is the principal gap junction protein expressed in osteoblasts and osteocytes, where it has been implicated in transmitting hormonal, mechanical load and growth factor induced signals [1,2]. Mutation of connexins has been implicated in several diseases [3-5]. Point mutations in GJA1, the gene encoding the gap junction protein $\mathrm{Cx} 43$, result in the human pleiotropic disorder oculodentodigital dysplasia, which includes skeletal manifestations [6]. Mouse models of oculodentodigital dysplasia $[7,8]$ and Cx43 genetic

\footnotetext{
* Correspondence: jstai002@umaryland.edu
Department of Orthopaedics, University of Maryland, School of Medicine,

* Correspondence: jstai002@umaryland.edu Baltimore, MD, USA
}

(C) 2010 Niger et al; licensee BioMed Central Ltd. This is an Open Access article distributed under the terms of the Creative Commons Attribution License (http://creativecommons.org/licenses/by/2.0), which permits unrestricted use, distribution, and reproduction in any medium, provided the original work is properly cited. Cx43 in skeletal function. However, little is known about the molecular mechanisms by which gap junctions regulate the function of skeletal tissues.

Using osteoblast cell lines, we have demonstrated that Cx43 can modulate growth factor responses and signal transduction cascades, leading to altered gene expression and osteoblast function [12-14]. We have recently reported that modulation of $\mathrm{Cx} 43$ can affect signal transduction in response to fibroblast growth factor 2 (FGF2) in a protein kinase C-delta (PKC $\delta$ )-dependent manner in osteoblasts [14]. PKC $\delta$ is a member of the novel PKCs, which, unlike classic PKCs, are calciumindependent but are activated by diacylglycerol and phosphatidylserine. In a previous study, we demonstrated that overexpression of $\mathrm{Cx} 43$ in a mouse osteoblast cell line could enhance the transcriptional response of the osteocalcin gene promoter to FGF2 treatment; an effect that could be abrogated by inhibition of PKC $\delta$ expression or activity [14]. Conversely, inhibition of $\mathrm{Cx} 43$ expression could attenuate the ability of these cells to respond to FGF2. From these data, we hypothesize that $\mathrm{Cx} 43$ may recruit $\mathrm{PKC} \delta$ locally to the 
gap junction plaque where it can respond to second messengers being propagated through the gap junction channel. Indeed, numerous studies have shown that Cx43 can serve as a docking platform for signal complexes, including $\beta$-catenin, src, PKC $\alpha$ and $\mathrm{PKC} \varepsilon$ [15-18]. The novel PKC family member, PKC $\delta$, has not been shown to interact with $\mathrm{Cx} 43$. Accordingly, we set out to examine the biochemical interactions between Cx43 and PKC $\delta$ as it relates to the effects of FGF2 signaling. By understanding these biochemical interactions, we gain insight into the biologically relevant signals that may be propagated through gap junction channels as well as a greater understanding of how gap junctions regulate signal transduction cascades and, ultimately, cell function.

\section{Results}

\section{$P K C \delta$-dependent phosphorylation of $C_{x} 43$}

Whole cell extracts were prepared from MC3T3 osteoblasts following treatment with vehicle (phosphate buffered saline, $0.1 \%$ bovine serum albumin, $1 \mathrm{mM}$ dithiothreitol), FGF2 (5 ng/ml) or phorbol 12-myristate 13-acetate (PMA, $200 \mathrm{nM}$ ) for up to 30 minutes. Western blots probed with anti-phospho-PKC $\delta$ (Thr505) antibodies reveal that treatment with FGF2 $(5 \mathrm{ng} / \mathrm{ml})$ increases the phosphorylation of PKC $\delta$ by 5 minutes, increasing further by 30 minutes (Figure 1A). Antibodies against phospho-Cx43 (Ser368) reveal that FGF2 treatment induces a concomitant phosphorylation of $\mathrm{Cx} 43$ at serine 368, a known target of PKC-mediated phosphorylation (Figure 1A). We observe similar results with PMA treatments, a positive control for PKC phosphorylation at threonine 505 and $\mathrm{Cx} 43$ phosphorylation at serine 368 [19]. Pre-treatment of MC3T3 cells with the PKC inhibitor rottlerin ( 3 and $5 \mu \mathrm{M}$ ) prevents the FGF2induced phosphorylation of $\mathrm{Cx} 43$ at serine 368 (Figure 1B). This suggests that PKC $\delta$ phosphorylates $C x 43$ and that the two proteins physically interact, at least transiently, during FGF2 treatment.

\section{Immunofluorescent detection of PKC $\delta$ and $\mathrm{Cx} 43$}

In order to examine the subcellular localization of activated PKC $\delta$, MC3T3 cells treated with vehicle or $5 \mathrm{ng} /$ $\mathrm{ml}$ FGF2, for the indicated times, were fixed and stained with anti-phospho-PKC $\delta$ (Thr505) antibodies (Figure 2A). By immunofluorescence microscopy, we examined the localization of phospho-PKC $\delta$ (Thr505) in osteoblasts over a time course following exposure to FGF2. While classic PKCs are rapidly translocated to the plasma membrane upon activation, PKC $\delta$ has been shown to translocate not only to the plasma membrane but also to the nucleus $[20,21]$. Prior to treatment with FGF2 (Figure 2A, $0 \mathrm{~min}$ ), phospho-PKC $\delta$ is detected diffusely throughout the cytoplasm and in defined foci in the nuclei. Occasional, weak staining is observed at the periphery of cells. In contrast, within 10 minutes of exposure to FGF2, there is a rapid accumulation of phospho-PKC $\delta$ staining observed in the nuclear compartment (Figure 2A, $10 \mathrm{~min}$ ). Interestingly, we did not see a generalized staining of the plasma membrane with anti-phospho-PKC $\delta$ antibodies, rather we noticed a distinct pattern of staining near the point of cell-cell contacts, that is remindful of the staining we see for Cx43 in these cells. The apparent accumulation of phospho$\mathrm{PKC} \delta$ staining at cell-cell contacts remained at $20 \mathrm{~min}-$ utes following FGF2 stimulation (Figure 2A, $20 \mathrm{~min}$ ). To determine if PKC $\delta$ is accumulating at the plasma membrane, we prepared protein extracts on plasma membrane preparations from osteoblasts during a time course of FGF2 treatment. Subsequent, western blots of these plasma membrane extracts were probed with antiPKC $\delta$, anti-phospho-PKC $\delta$ (Thr505) and anti-Cx43 antibodies. There is a notable accumulation of PKC $\delta$ and phospho-PKC $\delta$ in the membrane protein extract following treatment with FGF2 for 5 minutes (Figure 2B). This accumulation at the plasma membrane is transient, however, as it begins to diminish 30 minutes after FGF2 administration. Cx43 levels in the membrane fraction remain relatively static (Figure $2 \mathrm{~B}$ ). Importantly, both proteins are found in the plasma membrane fraction, thus allowing for a potential protein-protein interaction.

Given that both proteins are found in the plasma membrane and possess similar patterns of staining, we next sought to see if the pattern of staining observed with phospho-PKC $\delta$ antibodies following FGF2 administration was consistent with localization at $\mathrm{Cx} 43$ gap junction plaques. Accordingly, we performed immunofluorescent co-detection of both phospho-PKC $\delta$ (Thr505) and Cx43. Cx43 is diffusely detected throughout the cytoplasm with distinct areas of bright, punctate fluorescence at the periphery of the cells, near cell-cell borders (Figure 3i). PKC $\delta$ is primarily observed at the nuclear compartment of these cells, though a similar pattern of fluorescence accumulation in defined regions at cell-cell borders is observed (Figure 3ii). When the fluorescent images are merged, there is a distinct codetection of both PKC $\delta$ and $\mathrm{Cx} 43$ in punctate clusters near cell-cell contacts, consistent with the expected pattern of staining seen at gap junction plaques (Figure 3iv). Importantly, while this immunofluorescent co-detection of PKC $\delta$ and $\mathrm{Cx} 43$ does not confirm any protein-protein interaction, it provides critical feasibility that the two proteins are located in situ in a manner that could permit protein-protein interactions.

\section{Co-immunoprecipitation of Cx43 and PKC $\delta$}

Next, we attempted to establish protein-protein interactions between $\mathrm{Cx} 43$ and PKC $\delta$ by biochemical means. 


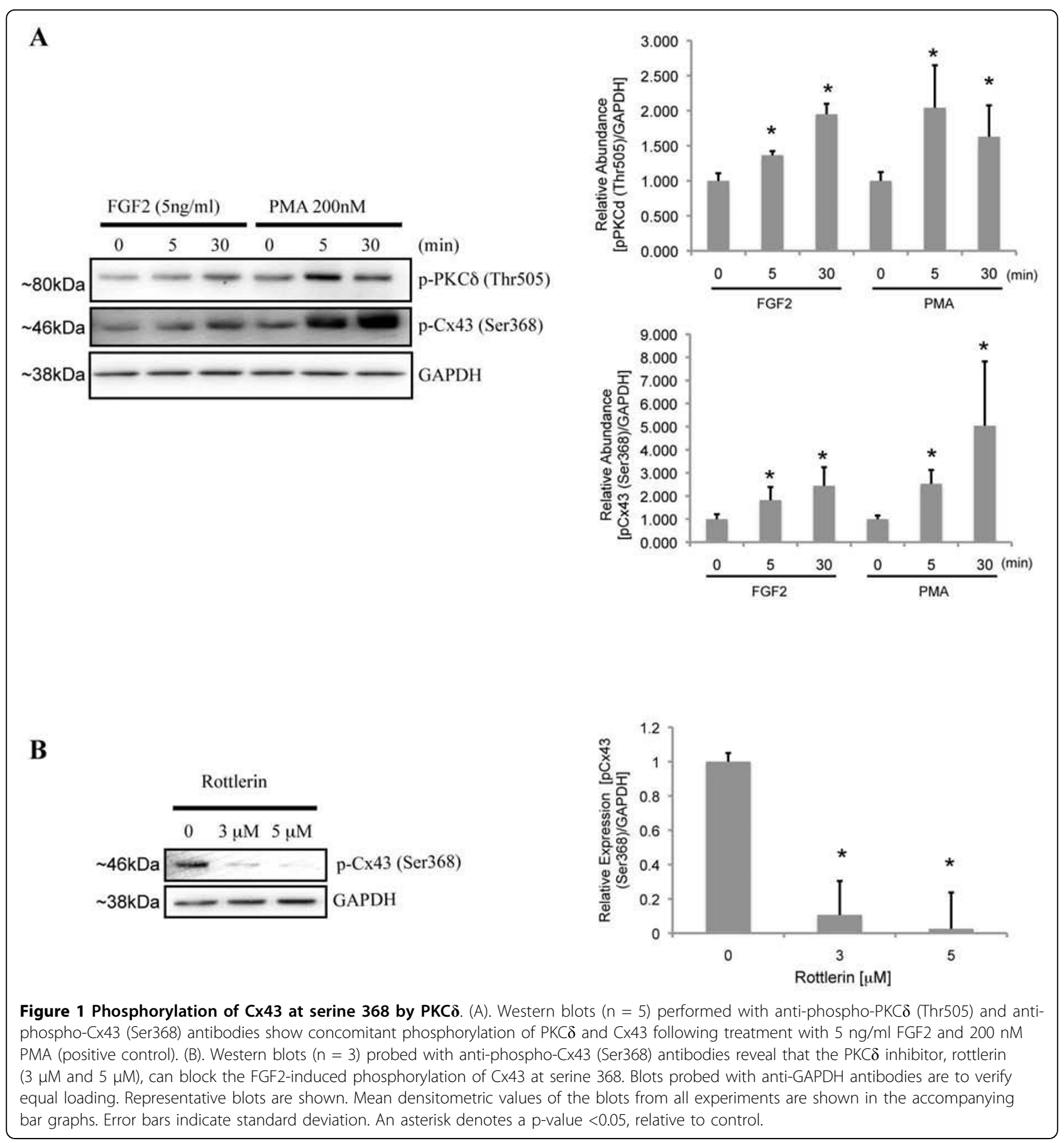

We performed co-immunoprecipitation experiments from whole cell extracts isolated from MC3T3 cells. Previous studies have shown that PKC $\alpha$ and PKC $\varepsilon$ can interact with $C \times 43[22,23]$. As a result, we used an antipanPKC antibody and an anti-PKC $\varepsilon$ antibody as controls to ensure the efficacy of our co-immunoprecipitations. First, we confirmed the specificity of the antibodies to be used for co-immunoprecipitation experiments by western blotting MC3T3 whole cell extracts (Figure 4A).
As expected, we detect the presence of PKC $\delta, P K C \varepsilon$ and Cx43 in MC3T3 cells. Additionally, the abundance of these factors was not appreciably affected by treatment of the cells for 15 minutes with FGF2 $(5 \mathrm{ng} / \mathrm{ml})$. Next, we examined whether anti-Cx43 antibodies could be used to co-immunoprecipitate PKC family members, including $\mathrm{PKC} \delta$. Immunoprecipitations were performed with non-immune IgG, anti-PKC or anti-Cx43 antibodies, and western blots of supernatant (S) and bead (B) 
$\mathbf{A}$
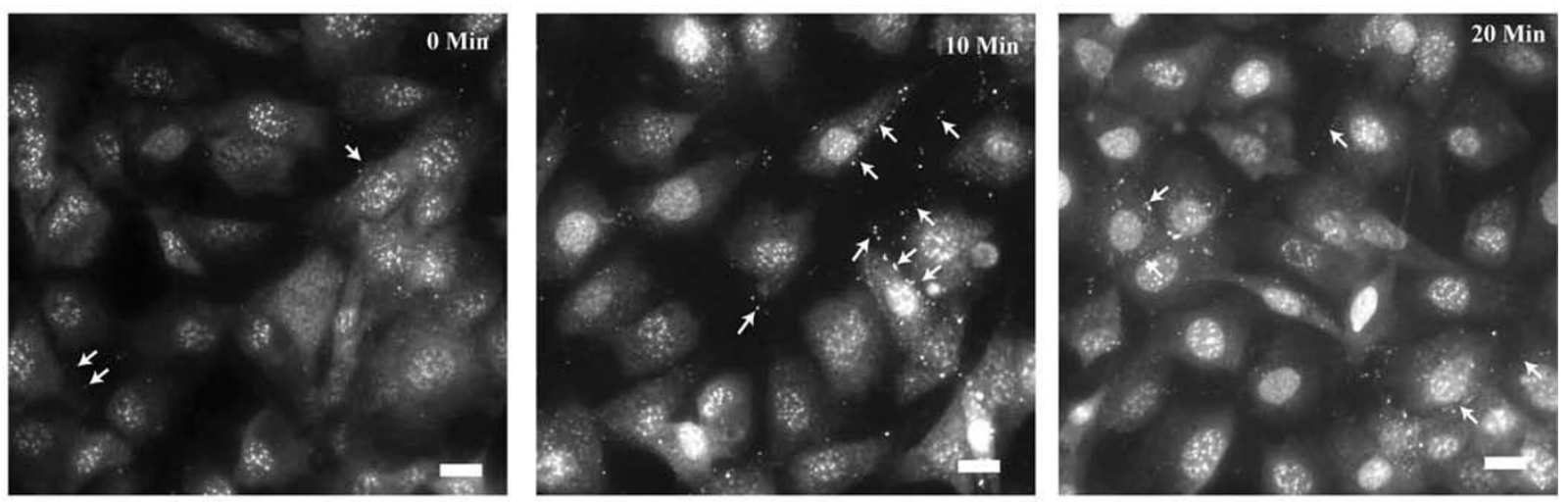

phospho-PKCס (Thr505)

B

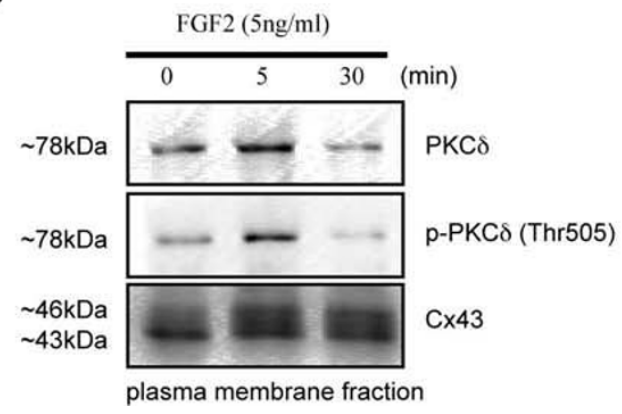

Figure 2 FGF2 induces the accumulation of phospho-PKC $\delta$ in both the nuclei and plasma membrane. (A). Serum starved MC3T3 cells were subjected to immunofluorescent detection with anti-phospho-PKC $\delta$ (Thr505) antibodies during a time course of treatment with FGF2 $(5 \mathrm{ng} / \mathrm{ml})$. Representative images collected by epi-fluorescence microscopy are shown for each time point. Small arrows indicate the punctate staining at the cell periphery. The scale bar indicates $\sim 10 \mu \mathrm{m}$. (B) Western blots $(n=3)$ probed with anti-PKC $\delta$, anti-phospho-PKC $\delta$ (Thr505) and anti-Cx43 antibodies were performed on equal amounts of plasma membrane protein extracts from FGF2 (5 $\mathrm{ng} / \mathrm{ml})$ treated osteoblasts. Representative blots are shown.

fractions from the immunoprecipitations were probed with anti-panPKC, anti-PKC $\delta$ and anti-PKC $\varepsilon$ specific antibodies, as indicated in Figure 4B. In all cases, nonimmune IgG failed to immunoprecipitate PKCs. As expected, anti-PKC isoform antibodies were able to immunoprecipitate PKCs. Importantly, anti-Cx43 antibodies were able to co-immunoprecipitate proteins detectable with all three anti-PKC antibodies, supporting a protein-protein interaction between PKCs $(\alpha, \delta$ and $\varepsilon)$ and $\mathrm{Cx} 43$.

Next, we attempted the opposing co-immunoprecipitation, using anti-PKC antibodies to co-immunoprecipitate $\mathrm{Cx} 43$. Immunoprecipitations were performed with non-immune IgG, anti-Cx43, or anti-PKC antibodies, and western blots of supernatant (S) and bead (B) fractions from the immunoprecipitations were probed with anti-Cx43 specific antibodies, as indicated in Figure 4C. Non-immune IgG failed to immunoprecipitate PKCs. As expected, anti-Cx43 antibodies were able to immunoprecipitate $\mathrm{Cx} 43$ protein. Antibodies against panPKC, $\mathrm{PKC} \delta$ and $\mathrm{PKC} \varepsilon$ precipitate two products that are detected with $\mathrm{Cx} 43$ antibodies, $\mathrm{a} \sim 43 \mathrm{kD}$ and a $\sim 46$ $\mathrm{kD}$ protein. The $\sim 43 \mathrm{kD}$ protein is the non-phosphorylated (NP) form of $\mathrm{Cx} 43$, while the $\sim 46 \mathrm{kD}$ protein is a phosphorylated form of $\mathrm{Cx} 43$ ( $\mathrm{p}-\mathrm{Cx} 43$ ). Interestingly, it would appear that phosphorylated Cx43 ( 46 kD) is preferentially associated with all three PKCs, as this is the principal product detected in the bead fractions from co-immunoprecipitations with anti-PKC antibodies (Figure 4C, lanes 5,7 and 9), in contrast to the predominance of the $\sim 43 \mathrm{kDa}$ band (NP form) that is observed in the $\mathrm{Cx} 43$ direct immunoprecipitation (Figure 4C, lane 3).

To validate that this $\sim 46 \mathrm{kD}$ product corresponds to phosphorylated Cx43, co-immunoprecipitations were performed using non-immune IgG, anti-Cx43 and antiphospho-PKC $\delta$ antibodies, and the immunoprecipitated products were probed by western blotting with anti-Cx43 

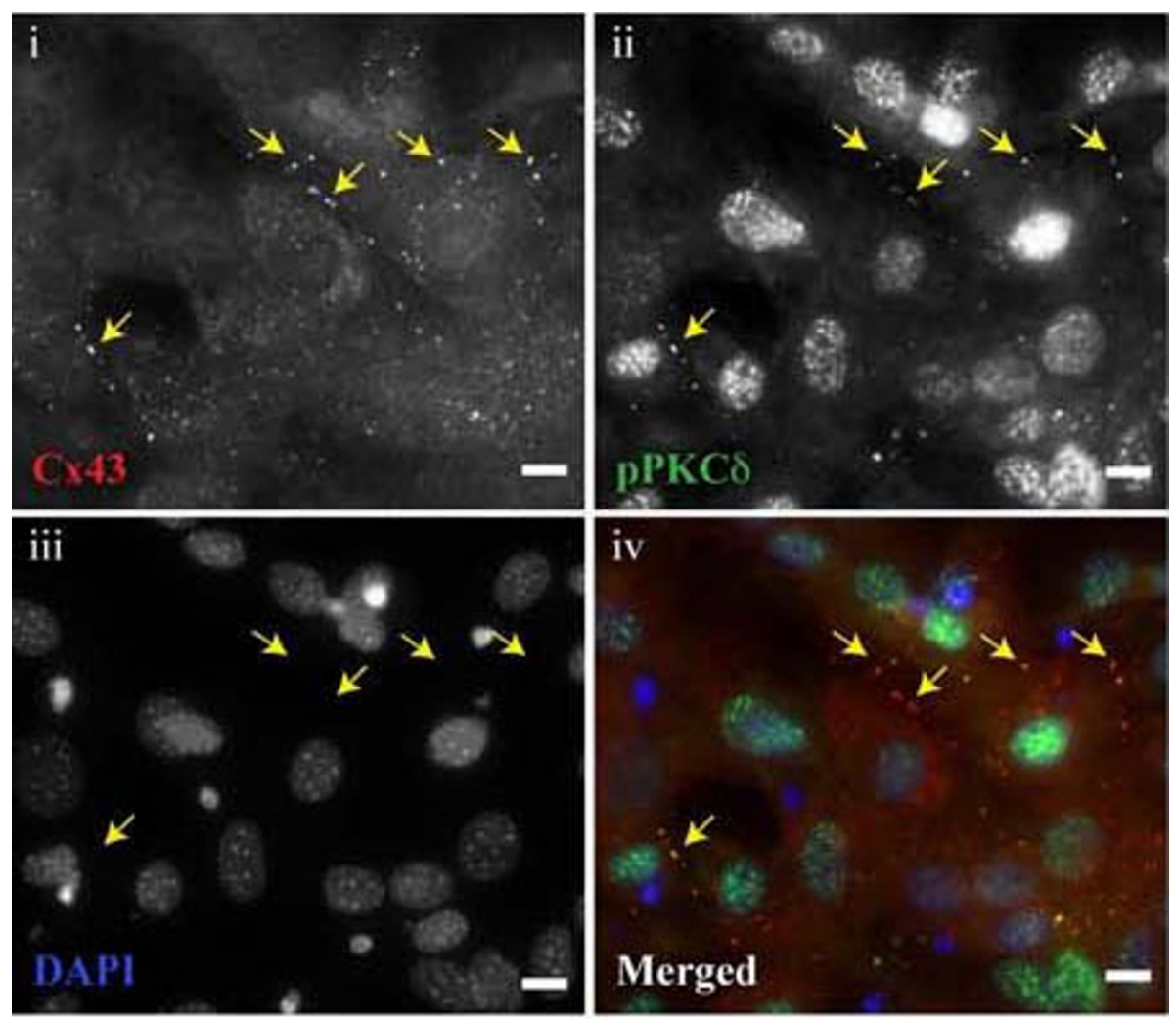

Figure 3 Co-detection of $\mathbf{C x} 43$ and phospho-PKC $\delta$ at the plasma membrane. Serum starved MC3T3 cells were treated with FGF2 for 10 min prior to fixation and subsequent staining with (i) mouse anti-Cx43 (red), (ii) rabbit anti-phospho-PKC $\delta$ (Thr505) (green), (iii) DAPI (blue). A merged image is also shown (iv). Arrows indicate the same position on each panel and correspond to areas where both Cx43 and phospho-PKC $\delta$ appear to be closely co-detected in their respective panels. A representative field of view is shown. The white scale bar is $\sim 10 \mu \mathrm{m}$.

or anti-phospho-serine specific antibodies. The same noticeable enrichment of the higher molecular weight product $(\sim 46 \mathrm{kDa})$ is observed in the co-immunoprecipitations of Cx43 with anti-PKC antibodies in comparison to the direct $\mathrm{Cx} 43$ immunoprecipitation. (Figure 4D). In support of the notion that the $46 \mathrm{kDa}$ protein is a phosphorylated form of $\mathrm{Cx} 43$, the antiphospho-serine antibody strongly reacts with the $\sim 46 \mathrm{kDa}$ product in the co-immunoprecipitations with anti-PKC $\delta$ antibodies (Figure 4D). These data reinforce the hypothesis that $\mathrm{PKC} \delta$ preferentially associates with phospho-Cx43.

We have previously shown that $\mathrm{PKC} \delta$ (but not $\mathrm{PKC}$ ) translocates to the nucleus of FGF2 treated osteoblasts by 30 minutes [14]. At intermediate time points following FGF2 treatment, there is a distinct accumulation of PKC $\delta$ in nodules at the plasma membrane, as shown in Figures 2 and 3. To determine the kinetics of association between $C x 43$ and PKC $\delta$ in FGF2 treated osteoblasts, MC3T3 cells were treated with FGF2 for 0,10 and 20 minutes. Whole cell extracts were immunoprecipitated with non-immune IgG or anti-PKC $\delta$ antibodies and western blots of supernatant (S) and bead (B) fractions from the immunoprecipitations were probed with antiCx43 antibodies, as shown in Figure 5. There is a distinct increase in the Cx43/PKC $\delta$ interaction following 10 minutes of exposure to FGF2 ( 1.5 fold increase in co-immunoprecipitated $\mathrm{Cx} 43$ versus input, relative to untreated samples). This association is transient, however, as the $\mathrm{Cx} 43 / \mathrm{PKC} \delta$ interaction is reduced to below basal levels by 20 minutes ( 1.5 fold decrease in coimmunoprecipitated $\mathrm{Cx} 43$ versus input, relative to untreated samples). By 40 minutes of FGF2 treatment, we are unable to co-precipitate $\mathrm{Cx} 43$ and $\mathrm{PKC} \delta$ (data not shown). This data is consistent with the kinetics of cellular re-distribution of PKC $\delta$ following FGF2 treatment, shown in Figure 2.

\section{GST pulldown of PKC $\delta$ with the Cx43 C-terminal tail}

Finally, in order to confirm that the association between PKC $\delta$ and $C x 43$ occurs in the C-terminal domain of Cx43, we performed GST-pulldown assays, using a recombinant GST-Cx43 fusion protein that spans amino acids 241-382 of the Cx43 C-terminal tail 
(GST-Cx43CT). We anticipated association of PKC $\delta$ with the $\mathrm{C}$-terminal tail of $\mathrm{Cx} 43$ because this domain is commonly associated with the assembly of signal complexes [15-18] and includes characterized PKC phosphorylation sites [19].

Recombinant, purified GST-Cx43CT or GST-alone were crosslinked to glutathione sepharose $4 \mathrm{~B}$ beads. The crosslinked beads were then used to pulldown interacting proteins from MC3T3 whole cell extracts. The input and bead fractions were then western blotted with antiPKC $\delta$ antibodies. GST-Cx43CT(241-382)-conjugated beads could strongly pull down PKC $\delta$ from MC3T3 whole cell extracts (Figure 6). Beads conjugated to GST alone were unable to pull down PKC $\delta$. Specificity of the GST-pulldown was confirmed by probing the western blot with anti-GAPDH antibodies, which revealed an immunoproduct in the input fraction but not in either bead fraction (data not shown).

\section{Discussion}

Previously, we have shown that modulation of $\mathrm{Cx} 43$ protein levels can affect the impact of FGF2 on 

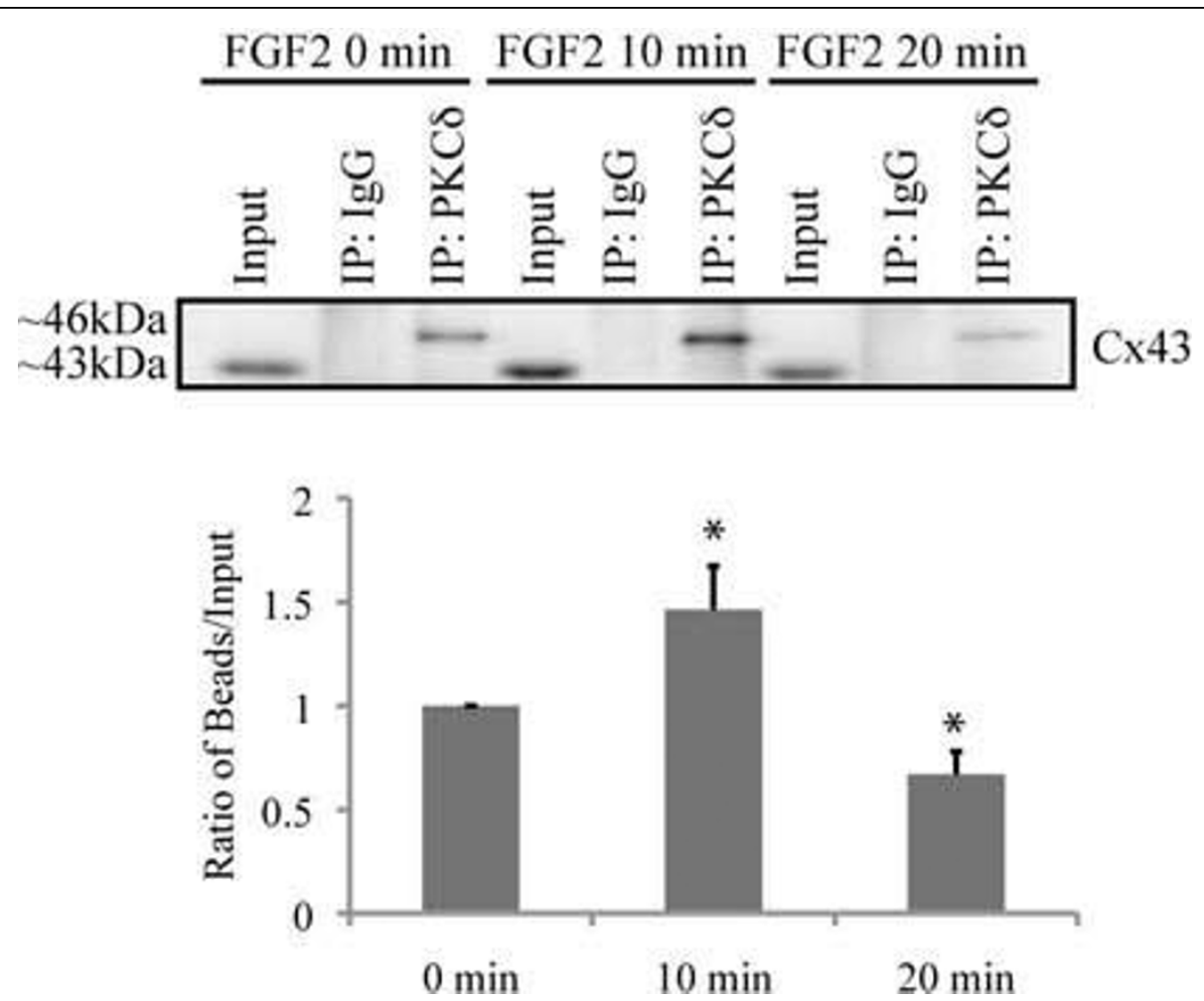

Figure 5 FGF2 treatment promotes a transient increase in association of Cx43 and phospho-PKC $\boldsymbol{\delta}$. Whole cell extracts were prepared from cells treated with vehicle or $5 \mathrm{ng} / \mathrm{ml} \mathrm{FGF2} \mathrm{for} \mathrm{the} \mathrm{indicated} \mathrm{time.} \mathrm{The} \mathrm{extracts} \mathrm{were} \mathrm{immunoprecipitated} \mathrm{(IP)} \mathrm{with} \mathrm{non-immune} \mathrm{lgG,} \mathrm{anti-}$ Cx43, or anti-phospho-PKC $\delta$ (Thr505) antibodies, as indicated. A fraction of the input and the bead fractions from the immunoprecipitations were subjected to western blotting (WB) with anti-Cx43 antibodies. The co-precipitated Cx43 and phospho-PKC $\delta$ complex is most abundant at 10 minutes and returns to basal levels by 15 minutes. The graph reveals the average ratio of co-immunoprecipitated Cx43 relative to the Cx43 present in the input fraction for each time point from three separate experiments. Error bars indicate standard deviation. An asterisk denotes a p-value $<0.05$, relative to control. The ratio for the 0 min FGF2 treatment point has been arbitrarily set to a value of 1.

osteoblast transcription in a $\mathrm{PKC} \delta$-dependent manner [14]. In that study, we reported that over expression of Cx43 potentiates the transcriptional response to FGF2 by enhancing the activation and mobilization of PKC $\delta$ in the cell, which ultimately increases transcription of the osteoblast specific gene, osteocalcin. Conversely, we show that inhibition of $\mathrm{Cx} 43$ expression or function could inhibit the responsiveness of the osteocalcin gene to FGF2 treatment. These data established the involvement of $\mathrm{Cx} 43$ and $\mathrm{PKC} \delta$ in the osteoblast response to FGF2, however, it remained undetermined how the relative abundance of $\mathrm{Cx} 43$ could impact PKC $\delta$ function.

Several studies have shown that FGF2 can activate PKC [24-29], or that FGF2 can increase phosphorylation of Cx43 [22,30,31]. Additionally, the activation of PKC isoforms, by phorbol esters has been shown to result in the inhibition of gap junctional communication [19,32-35]. However, a physical interaction of PKC $\delta$ with $\mathrm{Cx} 43$ has never been reported, nor has FGF2 been shown to increase phosphorylation of $\mathrm{Cx} 43$ in a $\mathrm{PKC} \delta$ dependent manner.
In this study, we demonstrate via immunofluorescence staining and biochemical methods that $\mathrm{PKC} \delta$ physically interacts with Cx43. While alone, the immunofluorescence does not prove a physical interaction, we think that this data provides strong support of the feasibility of a physical interaction in situ and that the co-precipitation studies are biologically relevant. We go on to characterize the kinetics of the phosphorylation, interaction and cellular translocation following FGF2 treatment, revealing a transient association of PKC $\delta$ with $\mathrm{Cx} 43$ at the plasma membrane and subsequent accumulation of PKC $\delta$ in the nucleus following treatment with FGF2. Our study is the first to show that PKC $\delta$ can physically interact with $\mathrm{Cx} 43$ in osteoblastic cells, and that there is a PKC $\delta$-dependent phosphorylation of $\mathrm{Cx} 43$ at serine 368 that occurs in response to FGF2 administration. It is likely that multiple phosphorylations of $\mathrm{Cx} 43$ occur, in addition to the one detected at serine 368 , as phosphorylation of serine 368 alone is not sufficient to result in the observed molecular weight shift of $\mathrm{Cx} 43$ on SDS-PAGE gels to $\sim 46 \mathrm{kDa}$ [36-38]. 


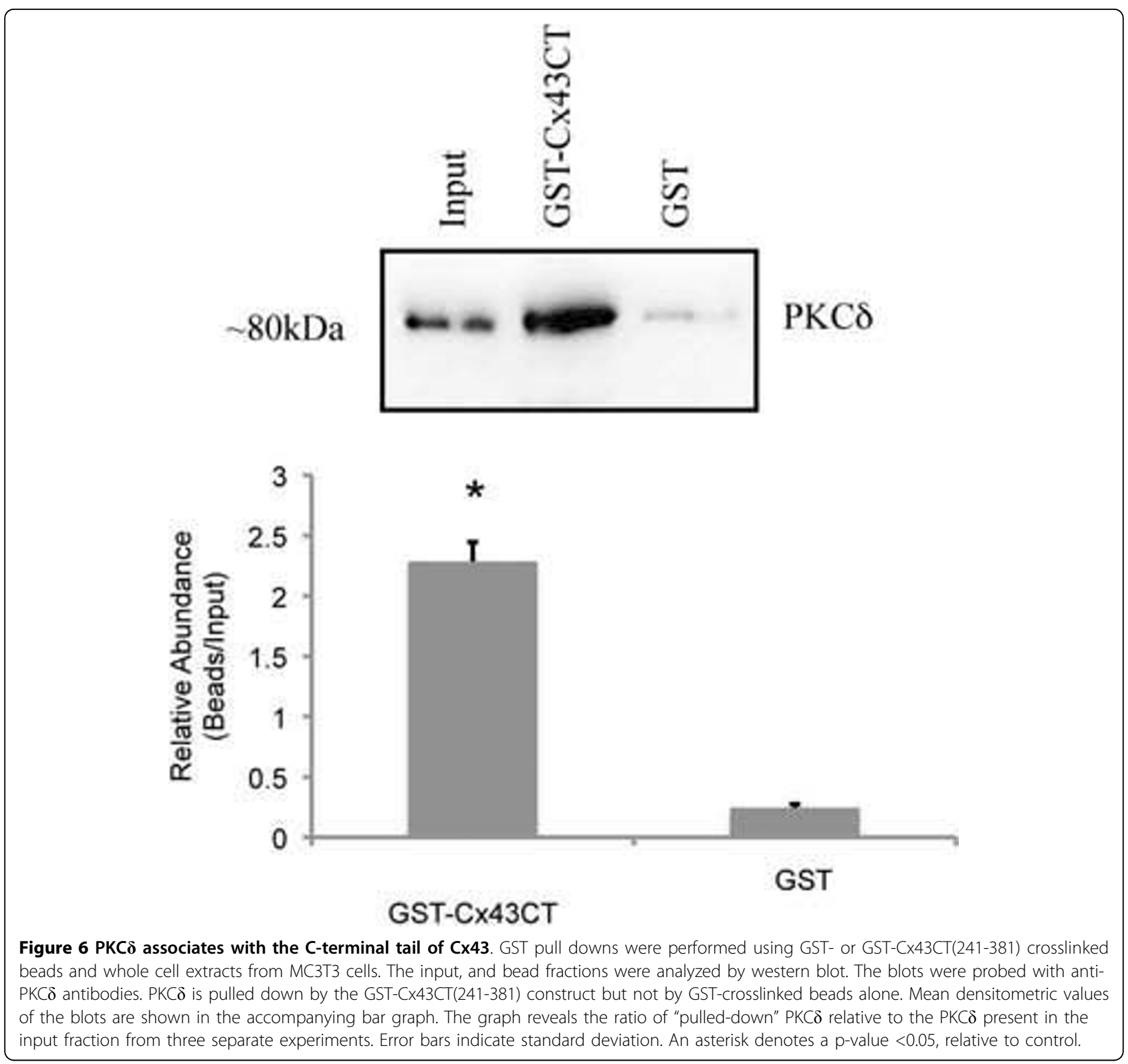

A similar interaction between $\mathrm{Cx} 43$ and another novel PKC family member, $\mathrm{PKC} \varepsilon$, has been reported following FGF2 treatment in cardiomyocytes [22]. It is unclear whether the involvement of PKC $\delta$ in the FGF2-response and association with $\mathrm{Cx} 43$ also occurs in cardiomyocytes, or whether this is an osteoblast-specific interaction. It would not be surprising that $\mathrm{PKC} \delta$ could also associate with $\mathrm{Cx} 43$ in cardiomyocytes, as FGF2, $\mathrm{PKC} \varepsilon$, PKC $\delta$ and $C x 43$ have all been implicated in cardioprotection following ischemia [39-43]. Notably, in a previously reported study in osteoblasts, we did not detect a translocation of PKCE following FGF2 treatment in these cells, suggesting distinct roles for PKC $\delta$ and $\mathrm{PKC} \varepsilon$ in the FGF2-response of bone forming cells [14].
In this study, we report that $\mathrm{PKC} \delta$ physically interacts with the C-terminal tail of $\mathrm{Cx} 43$. We speculate that the preferential interaction of $\mathrm{PKC} \delta$ with the phosphorylated form of $\mathrm{Cx} 43$ is because PKC $\delta$ directly phosphorylates $\mathrm{Cx} 43$ (i.e., $\mathrm{Cx} 43$ is a substrate for $\mathrm{PKC} \delta$ ). The fact that inhibition of PKC $\delta$ activity with rottlerin can prevent phosphorylation of Cx43 at serine 368 indicates that, at a minimum, PKC $\delta$ lies upstream of $\mathrm{Cx} 43$ phosphorylation, and that $\mathrm{Cx} 43$ may be a direct substrate for PKC $\delta$. Alternately, it is possible that the phosphorylation of $\mathrm{Cx} 43$ is a prerequisite for the docking of PKC $\delta$ with the Cx43 C-terminal tail. Future studies will explore these alternatives. It should also be noted that, while commonly used as an inhibitor of $\mathrm{PKC} \delta$, the specificity of rottlerin has been questioned [44]. 
In total, these data support our model that $\mathrm{Cx} 43$ affects osteoblast function by regulating signal transduction cascades. We predict that intercellular communication via gap junctions results in the sharing of signals/ second messengers among coupled osteoblasts, permitting cells to respond more robustly to extracellular stimuli, such as growth factors, hormonal signals or mechanical load. Central to this model is the concept that $\mathrm{Cx} 43$ serves as a docking platform for signaling complexes, recruiting them to the gap junction plaque where they can respond to transmitted signals/second messengers. Previously, we had identified PKC $\delta$ as a mediator of the $\mathrm{Cx} 43$ enhanced response of osteoblast to FGF2 but, it was unknown whether or not PKC $\delta$ was recruited to the $\mathrm{Cx} 43$ gap junction plaque to participate in signaling [14]. Now, we can add PKC $\delta$ to the growing number of signaling complexes that are recruited to and participate in signaling at the gap junction plaque.

By establishing the protein-protein interactions that can occur between gap junctions and signaling complexes, we gain valuable insights into the molecular mechanisms by which gap junctions/connexins can affect cellular signaling to ultimately affect cell function. Additionally, we learn how gap junctions themselves may be regulated. Indeed, phosphorylation of $\mathrm{Cx} 43$ can affect its function/transport, including assembly of hemichannels, transport to the plasma membrane, channel gating and turnover $[36,45]$. Furthermore, the clarification of these interactions lends insights into the biologically relevant molecules that may be propagated through gap junction channels. The activation of several signaling cascades downstream of the FGF2-FGF receptor complex generates second messengers that may transverse the gap junction channel. Among the signal cascades activated by the FGF2-FGF receptor complex include Ras-ERK MAPK cascade, phospholipase $C \gamma$, phospholipase D and cytosolic phospholipase A2, which produce second messengers like inositol phosphate derivates, diacylglycerol, arachidonic acid, and calcium [46-52]. Of note, several of these second messengers have been shown to regulate PKC $\delta$ activation [21,53-56].

Importantly, it is equally plausible that the role of Cx43 in FGF-signaling is independent of its function as a permeable pore for direct cell-cell communications. Connexins have been widely implicated as functioning as unpaired hemichannels [57]. Furthermore, several studies have revealed important non-channel roles for connexins in cell function $[58,59]$. For example, it is possible that $\mathrm{Cx} 43$ may affect FGF2-initiated signaling cascades and osteoblast function by sequestering signal complexes to cellular microdomains, altering mitochondrial function, direct nuclear shuttling or affecting signal complex turnover, independent of cell-cell communication.
Future studies are needed to define the need for PKC $\delta$ protein docking with the $\mathrm{Cx} 43$ gap junction channel. More specifically, if the proximal recruitment of PKC $\delta$ to the Cx43-dependent "shared" messenger is required to transmit the amplification of the FGF2 response among osteoblasts. By studying the mechanism of action of gap junctions in transmitting signals among the cells of bone, we hope to be able to understand the role of gap junctions in how skeletal cells coordinate function during bone growth, remodeling and repair.

\section{Conclusion}

Cx43 can serve as a direct docking platform for the recruitment of $\mathrm{PKC} \delta$ in order to affect FGF2 signaling in osteoblasts. $\mathrm{PKC} \delta$ is found to transiently associate with $\mathrm{Cx} 43$ at cell-cell junctions, following stimulation with FGF2. Subsequently, PKC $\delta$ accumulates in the nucleus, where we have shown in a previous study that it alters transcription of key osteoblastic genes [14]. These data expand the list of signal molecules that assemble on the Cx43 C-terminal tail and provide a critical context to understand how gap junctions modify signal transduction cascades in order to impact cell function.

\section{Methods}

\section{Chemicals, Antibodies and Reagents}

Unless specified, chemicals were purchased from Sigma (St Louis, MO). Recombinant FGF2 was from R\&D Systems (Minneapolis, MN). FGF2 was reconstituted in a sterile vehicle solution (phosphate buffered saline, $0.1 \%$ bovine serum albumin, $1 \mathrm{mM}$ dithiothreitol). The sources of antibodies used were Sigma (rabbit anti-Cx43 (\#C6219) and mouse anti-phospho-serine (\#P5747) antibodies), Santa Cruz Biotechnology (Santa Cruz, CA; rabbit anti-panPKC (\#sC-10800), rabbit anti-PKCe (\#sc-214) and rabbit anti-PKC $\delta$ antibodies (\#sc-937)), Cell Signaling Technology (Beverly, MA; rabbit anti-phospho-Cx43 (Ser 368) (\#3511) and rabbit anti-phospho-PKC $\delta$ (Thr505) (\#9374), and Chemicon (Temecula, CA; mouse anti-Cx43 (\#MAB3067), anti-GAPDH (\#MAB374); and Millipore (Billerica, MA) FITC-conjugated donkey antirabbit IgG (\#AP182F), Cy3-conjugated donkey antimouse IgG antibodies(\#AP192C). The following reagents were also used: DAPI (4',6-Diamidine-2'-phenylindole dihydrochloride; Roche, Indianapolis, IN), Protein G PLUS/Protein A-Agarose beads (Calbiochem, La Jolla, CA), non-immune mouse and rabbit IgG antibodies (Calbiochem, San Diego, CA).

\section{Cell Culture and FGF2 Treatments}

MC3T3-E1 (clone 4) osteoblasts were purchased from the ATCC (Manassas, VA). These cells were cultured in DMEM (Cellgro, Herndon, VA) supplemented with $10 \%$ 
fetal bovine serum (Hyclone, Logan, UT) and a penicillin $(50 \mathrm{IU} / \mathrm{ml})$-streptomycin $(50 \mu \mathrm{g} / \mathrm{ml})$ solution (Cellgro) as described previously [14]. For experiments with FGF2 treatment, cells were serum-starved in DMEM containing $0.1 \%$ fetal bovine serum and $0.3 \%$ bovine serum albumin for 24 hours. FGF2 was added to the starvation media at $5 \mathrm{ng} / \mathrm{ml}$. The vehicle diluent for FGF2 (phosphate buffered saline, 0.1\% bovine serum albumin, $1 \mathrm{mM}$ dithiothreitol) was used as a negative control for FGF2 treatments. Cell viability was routinely monitored using a CCK-8 assay (Alexis Biochemicals, Farmingdale, NY). Cell viability was unaffected by FGF2 or inhibitor treatments when compared to vehicle treated cells. All experiments performed in this study were repeated at least three times, and data from representative experiments are shown.

\section{Western Blotting}

Whole cell extracts were prepared from confluent cultures of MC3T3 cells using a modified RIPA buffer (50 $\mathrm{mM}$ Tris, $\mathrm{pH} 8.0,150 \mathrm{mM} \mathrm{NaCl}, 10 \mathrm{mM}$ sodium pyrophosphate, $10 \mathrm{mM}$ sodium fluoride, $10 \mathrm{mM} \beta$-glycerophosphate, $1 \mathrm{mM}$ EGTA, $1 \mathrm{mM}$ EDTA, $2 \mathrm{mM}$ sodium vanadate, $1 \% \mathrm{NP}-40,0.5 \%$ sodium deoxycholate, $0.1 \%$ sodium dodecyl sulfate, and $1 \times$ protease inhibitor cocktail (Sigma)). For western blots using plasma membrane extracts, plasma membrane fractions were obtained and partially purified using a modified sucrose density gradient method [60]. Briefly, FGF2-treated MC3T3 cells from trypsinized cultures were centrifuged at $900 \mathrm{~g}$ at $4^{\circ} \mathrm{C}$ for 5 minutes and the resulting cell pellets were washed twice in cold HBSS (Cellgro). Cells were resuspended in cold hypotonic buffer (10 mM HEPES, $\mathrm{pH}$ 7.9, $1.5 \mathrm{mM} \mathrm{MgCl}_{2}, 10 \mathrm{mM} \mathrm{KCl}, 0.5 \mathrm{mM}$ DTT) with $1 \times$ protease inhibitor cocktail and $1 \mathrm{mM}$ sodium orthovanadate, and incubated on ice for $10 \mathrm{~min}$ to allow swelling. Cells were then lysed by adding 1\% NP-40. The resulting lysates were centrifuged $\left(1300 \mathrm{~g}, 10 \mathrm{~min} ., 4^{\circ} \mathrm{C}\right)$ to remove unbroken cells and nuclei. The supernatants were then loaded on top of sucrose gradients generated by layering a $10 \%$ sucrose $(\mathrm{w} / \mathrm{v})$ solution on top of a $60 \%$ sucrose solution. Following centrifugation $(45,500 \mathrm{~g}$, 30 min., $4^{\circ} \mathrm{C}$ ) enriched plasma membrane fractions were collected in between the $10 \%$ and $60 \%$ sucrose layers and stored at $-80^{\circ} \mathrm{C}$ until needed. For all western blots, equal amounts of proteins were electrophoresed on 10\% SDSPAGE gels, blotted to PVDF membranes and probed with the indicated antibodies. Membranes were stripped and re-probed with GAPDH antibodies to ensure equal loading of proteins among lanes. All blots were repeated at least three times with independent cell cultures. Representative data are shown for each. Where indicated, the band intensites of western blots were quantitated with ImageJ image analysis software (NIH, Bethesda,
MD). Data from multiple blots (a minimum of three) were normalized and averaged. Statistical significance was determined by one-way ANOVA and Tukey's post hoc test. A p-value of $<0.05$ was used as an indication of statistical significance.

\section{Immunofluorescence}

Cells grown to confluence on coverslips in 6-well plates were prepared for immunostaining, following FGF2 treatments for the indicated time. Samples were stained and imaged as previously described [14]. Staining using non-immune rabbit and mouse IgG and anti-rabbit FITC and anti-mouse Cy3 secondary antibodies were used as a negative control. All immunostaining experiments were performed on a minimum of two coverslips per experiment and repeated on at least three separate cultures. Up to four fields of view were imaged per coverslip. Representative images are shown for each experiment.

\section{Co-immunoprecipitations}

MC3T3 cells were harvested with IP buffer $(50 \mathrm{mM}$ Tris $\mathrm{pH}$ 8.0, $150 \mathrm{mM} \mathrm{NaCl}, 1.0 \%$ Triton- $x-100,10 \mathrm{mM}$ sodium pyrophosphate, $10 \mathrm{mM} \alpha$-glycerophosphate, $10 \mathrm{mM}$ sodium fluoride, $1 \mathrm{mM}$ EDTA, $1 \mathrm{mM}$ EGTA, $1 \mathrm{mM}$ sodium orthovanadate and $1 \times$ proteases inhibitor cocktail). Whole cell lysates (500 $\mu \mathrm{g}$ total proteins) were pre-cleared with protein $\mathrm{A} / \mathrm{G}$ agarose beads at $4^{\circ} \mathrm{C}$ for 60 minutes. The cleared supernatants were incubated overnight at $4^{\circ} \mathrm{C}$ with $2 \mu \mathrm{g}$ of the indicated antibodies, followed by a one-hour incubation at $4^{\circ} \mathrm{C}$ with protein $\mathrm{A} / \mathrm{G}$-agarose beads. After five washes in iced cold-PBS, the protein were eluted from the beads by heating the samples for 5 minutes at $95^{\circ} \mathrm{C}$ in Laemmli SDS buffer $(62.5 \mathrm{mM}$ Tris$\mathrm{HCl}, 2 \% \mathrm{w} / \mathrm{v}$ SDS, $10 \%$ glycerol, $50 \mathrm{mM} \mathrm{DTT}, 0.01 \% \mathrm{w} / \mathrm{v}$ bromophenol blue). A fraction of the eluted proteins (bead fraction) and supernatant (supe fraction) were then analyzed by western blotting (as described above) with the indicated antibodies.

\section{Glutathione-S-Transferase (GST) Pulldowns}

The region of the GJA1 gene corresponding to the Cterminal tail of the Cx43 protein (amino acids 241-382) were PCR amplified with the following forward and reverse primers: mCx43-EcoR1-241-Forward, GGAATTCCGTCTTCTTCAAGGGCGTT and mCx43Xhol-382-Reverse, CCGCTCGAGTTAAATCTCCAGGTCAGG. The gel purified Cx43 C-terminal tail PCR product was then subcloned into the EcoR1/XhoI sites of the pGEX-5X-2 vector (Amersham, Piscataway, $\mathrm{NJ}$ ) in-frame with an N-terminal GST tag. The resultant pGEX-Cx43CT (241-382) construct was used to generate purified GST-Cx43CT(241-382) protein, as we have published previously [61]. Empty pGEX-5X-2 vector was 
used to generate GST alone, to be used as a negative control. Equal amounts of purified GST - or GSTCx43CT(241-382) protein were covalently crosslinked to Glutathione Sepharose 4B beads (Amersham) with dimethyl pimelimidate. Immobilized GST - or GSTCx43CT (241-382) beads $(25 \mu \mathrm{l})$ were incubated with $100 \mu \mathrm{g}$ of MC3T3 whole cell extracts for 4 hours at $4^{\circ} \mathrm{C}$. After being washed five times in pulldown buffer (50 mM HEPES, pH 7.5, 1 mM EDTA, $150 \mathrm{mM} \mathrm{NaCl}, 10 \%$ glycerol, $0.1 \%$ Tween-20, $0.5 \mathrm{mM}$ DTT, protease inhibitor cocktail), the bound proteins were eluted and analyzed by western blotting.

\section{Acknowledgements}

This work was supported by a grant (R01-AR052719) from the National Institute of Arthritis, Musculoskeletal and Skin Diseases.

\section{Authors' contributions \\ CN performed the bulk of the experiments JS conceived the idea for this study, constructed the GST-Cx43CT plasmids, and supervised the experiments and data analysis. CH performed the GST-pulldown experiments. JS and CN wrote the manuscript. All authors read and approved the submitted manuscript.}

Received: 7 October 2009 Accepted: 25 March 2010

Published: 25 March 2010

\section{References}

1. Stains JP, Civitelli R: Gap junctions in skeletal development and function. Biochim Biophys Acta 2005, 1719(1-2):69-81.

2. Jiang JX, Siller-Jackson AJ, Burra S: Roles of gap junctions and hemichannels in bone cell functions and in signal transmission of mechanical stress. Front Biosci 2007, 12:1450-1462.

3. Laird DW: Life cycle of connexins in health and disease. Biochem J 2006, 394(Pt 3):527-543.

4. Wei CJ, Xu X, Lo CW: Connexins and cell signaling in development and disease. Annu Rev Cell Dev Biol 2004, 20:811-838.

5. Gerido DA, White TW: Connexin disorders of the ear, skin, and lens. Biochim Biophys Acta 2004, 1662(1-2):159-170.

6. Paznekas WA, Boyadjiev SA, Shapiro RE, Daniels O, Wollnik B, Keegan CE, Innis JW, Dinulos MB, Christian C, Hannibal MC, et al: Connexin 43 (GJA1) mutations cause the pleiotropic phenotype of oculodentodigital dysplasia. Am J Hum Genet 2003, 72(2):408-418.

7. Flenniken AM, Osborne LR, Anderson N, Ciliberti N, Fleming C, Gittens JE, Gong XQ, Kelsey LB, Lounsbury C, Moreno L, et al: A Gja1 missense mutation in a mouse model of oculodentodigital dysplasia. Development 2005, 132(19):4375-4386.

8. Dobrowolski R, Sasse P, Schrickel JW, Watkins M, Kim JS, Rackauskas M, Troatz C, Ghanem A, Tiemann K, Degen J, et al: The conditional connexin43G138R mouse mutant represents a new model of hereditary oculodentodigital dysplasia in humans. Hum Mol Genet 2008, 17(4):539-554.

9. Chung DJ, Castro CH, Watkins M, Stains JP, Chung MY, Szejnfeld VL, Willecke $K$, Theis M, Civitelli R: Low peak bone mass and attenuated anabolic response to parathyroid hormone in mice with an osteoblastspecific deletion of connexin43. J Cell Sci 2006, 119(Pt 20):4187-4198.

10. Lecanda F, Warlow PM, Sheikh S, Furlan F, Steinberg TH, Civitelli R: Connexin43 deficiency causes delayed ossification, craniofacial abnormalities, and osteoblast dysfunction. J Cell Biol 2000, 151(4):931-944.

11. Grimston SK, Brodt MD, Silva MJ, Civitelli R: Attenuated response to in vivo mechanical loading in mice with conditional osteoblast ablation of the connexin43 gene (Gja1). J Bone Miner Res 2008, 23(6):879-886.

12. Stains JP, Civitelli R: Gap junctions regulate extracellular signal-regulated kinase signaling to affect gene transcription. Mol Biol Cell 2005, 16(1):64-72.
13. Stains JP, Lecanda F, Screen J, Towler DA, Civitelli R: Gap junctional communication modulates gene transcription by altering the recruitment of Sp1 and Sp3 to connexin-response elements in osteoblast promoters. J Biol Chem 2003, 278(27):24377-24387.

14. Lima F, Niger C, Hebert C, Stains JP: Connexin43 potentiates osteoblast responsiveness to fibroblast growth factor 2 via a protein kinase Cdelta/Runx2-dependent mechanism. Mol Biol Cell 2009, 20(11):2697-2708.

15. Saez JC, Berthoud VM, Branes MC, Martinez AD, Beyer EC: Plasma membrane channels formed by connexins: their regulation and functions. Physiol Rev 2003, 83(4):1359-1400.

16. Giepmans BN: Gap junctions and connexin-interacting proteins. Cardiovasc Res 2004, 62(2):233-245.

17. Herve JC, Bourmeyster N, Sarrouilhe D: Diversity in protein-protein interactions of connexins: emerging roles. Biochim Biophys Acta 2004, 1662(1-2):22-41.

18. Herve JC, Bourmeyster N, Sarrouilhe D, Duffy HS: Gap junctional complexes: from partners to functions. Prog Biophys Mol Biol 2007, 94(12):29-65.

19. Lampe PD, TenBroek EM, Burt JM, Kurata WE, Johnson RG, Lau AF: Phosphorylation of connexin43 on serine 368 by protein kinase $C$ regulates gap junctional communication. J Cell Biol 2000, 149(7):1503-1512.

20. Martelli AM, Evangelisti C, Nyakern M, Manzoli FA: Nuclear protein kinase C. Biochim Biophys Acta 2006, 1761(5-6):542-551.

21. Steinberg SF: Distinctive activation mechanisms and functions for protein kinase Cdelta. Biochem J 2004, 384(Pt 3):449-459.

22. Doble BW, Ping $P$, Kardami $E$ : The epsilon subtype of protein kinase $C$ is required for cardiomyocyte connexin-43 phosphorylation. Circ Res 2000, 86(3):293-301.

23. Bowling N, Huang $X$, Sandusky GE, Fouts RL, Mintze K, Esterman M, Allen PD, Maddi R, McCall E, Vlahos CJ: Protein kinase C-alpha and -epsilon modulate connexin-43 phosphorylation in human heart. $J \mathrm{Mol}$ Cell Cardiol 2001, 33(4):789-798.

24. Im HJ, Muddasani P, Natarajan V, Schmid TM, Block JA, Davis F, van Wijnen AJ, Loeser RF: Basic fibroblast growth factor stimulates matrix metalloproteinase-13 via the molecular cross-talk between the mitogenactivated protein kinases and protein kinase Cdelta pathways in human adult articular chondrocytes. J Biol Chem 2007, 282(15):11110-11121.

25. Peluso JJ: Basic fibroblast growth factor (bFGF) regulation of the plasma membrane calcium ATPase (PMCA) as part of an anti-apoptotic mechanism of action. Biochem Pharmacol 2003, 66(8):1363-1369.

26. Peluso JJ, Pappalardo A, Fernandez G: Basic fibroblast growth factor maintains calcium homeostasis and granulosa cell viability by stimulating calcium efflux via a PKC delta-dependent pathway. Endocrinology 2001, 142(10):4203-4211.

27. Wert MM, Palfrey HC: Divergence in the anti-apoptotic signalling pathways used by nerve growth factor and basic fibroblast growth factor (bFGF) in PC12 cells: rescue by bFGF involves protein kinase $C$ delta. Biochem J 2000, 352(Pt 1):175-182.

28. Kim BG, Kim HJ, Park HJ, Kim YJ, Yoon WJ, Lee SJ, Ryoo HM, Cho JY: Runx2 phosphorylation induced by fibroblast growth factor-2/protein kinase $C$ pathways. Proteomics 2006, 6(4):1166-1174.

29. Kim HJ, Kim JH, Bae SC, Choi JY, Ryoo HM: The protein kinase C pathway plays a central role in the fibroblast growth factor-stimulated expression and transactivation activity of Runx2. J Biol Chem 2003, 278(1):319-326.

30. Srisakuldee W, Jeyaraman MM, Nickel BE, Tanguy S, Jiang ZS, Kardami E: Phosphorylation of connexin-43 at serine 262 promotes a cardiac injuryresistant state. Cardiovasc Res 2009, 83(4):672-681.

31. Srisakuldee W, Nickel BE, Fandrich RR, Jiang ZS, Kardami E: Administration of FGF-2 to the heart stimulates connexin-43 phosphorylation at protein kinase C target sites. Cell Commun Adhes 2006, 13(1-2):13-19.

32. Hawat $G$, Baroudi $G$ : Differential modulation of unapposed connexin 43 hemichannel electrical conductance by protein kinase $C$ isoforms. Pflugers Arch 2008, 456(3):519-527.

33. Kwak BR, van Veen TA, Analbers $L$, Jongsma HJ: TPA increases conductance but decreases permeability in neonatal rat cardiomyocyte gap junction channels. Exp Cell Res 1995, 220(2):456-463.

34. Liu TF, Johnson RG: Effects of TPA on dye transfer and dye leakage in fibroblasts transfected with a connexin 43 mutation at ser368. Methods Find Exp Clin Pharmacol 1999, 21(6):387-390. 
35. Bao X, Reuss L, Altenberg GA: Regulation of purified and reconstituted connexin 43 hemichannels by protein kinase C-mediated phosphorylation of Serine 368. J Biol Chem 2004, 279(19):20058-20066.

36. Solan JL, Lampe PD: Connexin43 phosphorylation: structural changes and biological effects. Biochem J 2009, 419(2):261-272.

37. Musil LS, Cunningham BA, Edelman GM, Goodenough DA: Differential phosphorylation of the gap junction protein connexin43 in junctional communication-competent and -deficient cell lines. J Cell Biol 1990, 111(5 Pt 1):2077-2088.

38. Solan JL, Fry MD, TenBroek EM, Lampe PD: Connexin43 phosphorylation at $\mathrm{S} 368$ is acute during $\mathrm{S}$ and $\mathrm{G} 2 / \mathrm{M}$ and in response to protein kinase $\mathrm{C}$ activation. J Cell Sci 2003, 116(Pt 11):2203-2211.

39. Boengler $K$, Schulz R, Heusch G: Connexin 43 signalling and cardioprotection. Heart 2006, 92(12):1724-1727.

40. Barnett ME, Madgwick DK, Takemoto DJ: Protein kinase $C$ as a stress sensor. Cell Signal 2007, 19(9):1820-1829.

41. Saffitz JE, Hames KY, Kanno S: Remodeling of gap junctions in ischemic and nonischemic forms of heart disease. J Membr Biol 2007, 218(13):65-71.

42. Churchill EN, Mochly-Rosen D: The roles of PKCdelta and epsilon isoenzymes in the regulation of myocardial ischaemia/reperfusion injury. Biochem Soc Trans 2007, 35(Pt 5):1040-1042.

43. Kardami E, Detillieux K, Ma X, Jiang Z, Santiago JJ, Jimenez SK, Cattini PA: Fibroblast growth factor-2 and cardioprotection. Heart Fail Rev 2007, 12(3-4):267-277.

44. Davies SP, Reddy H, Caivano M, Cohen P: Specificity and mechanism of action of some commonly used protein kinase inhibitors. Biochem J 2000, 351(Pt 1):95-105.

45. Solan JL, Lampe PD: Key connexin 43 phosphorylation events regulate the gap junction life cycle. J Membr Biol 2007, 217(1-3):35-41.

46. Mohammadi M, Honegger AM, Rotin D, Fischer R, Bellot F, Li W, Dionne CA, Jaye $M$, Rubinstein M, Schlessinger J: A tyrosine-phosphorylated carboxyterminal peptide of the fibroblast growth factor receptor $(\mathrm{Flg})$ is a binding site for the $\mathrm{SH} 2$ domain of phospholipase C-gamma 1. Mol Cell Biol 1991, 11(10):5068-5078.

47. Gotoh N: Regulation of growth factor signaling by FRS2 family docking/ scaffold adaptor proteins. Cancer Sci 2008, 99(7):1319-1325.

48. Ahmed A, Plevin R, Shoaibi MA, Fountain SA, Ferriani RA, Smith SK: Basic FGF activates phospholipase $D$ in endothelial cells in the absence of inositol-lipid hydrolysis. Am J Physiol 1994, 266(1 Pt 1):C206-212.

49. Sa G, Das T: Basic fibroblast growth factor stimulates cytosolic phospholipase $\mathrm{A} 2$, phospholipase C-gamma1 and phospholipase D through distinguishable signaling mechanisms. Mol Cell Biochem 1999, 198(1-2):19-30.

50. Oh DY, Park SY, Cho JH, Lee KS, Min do S, Han JS: Phospholipase D1 activation through Src and Ras is involved in basic fibroblast growth factor-induced neurite outgrowth of H19-7 cells. J Cell Biochem 2007, 101(1):221-234.

51. Dailey L, Ambrosetti D, Mansukhani A, Basilico C: Mechanisms underlying differential responses to FGF signaling. Cytokine Growth Factor Rev 2005, 16(2):233-247.

52. Raucci A, Bellosta P, Grassi R, Basilico C, Mansukhani A: Osteoblast proliferation or differentiation is regulated by relative strengths of opposing signaling pathways. J Cell Physio/ 2008, 215(2):442-451.

53. Gschwendt M: Protein kinase C delta. Eur J Biochem 1999, 259(3):555-564.

54. Dempsey EC, Newton AC, Mochly-Rosen D, Fields AP, Reyland ME, Insel PA, Messing RO: Protein kinase $C$ isozymes and the regulation of diverse cell responses. Am J Physiol Lung Cell Mol Physiol 2000, 279(3):L429-438.

55. O'Flaherty JT, Chadwell BA, Kearns MW, Sergeant S, Daniel LW: Protein kinases $C$ translocation responses to low concentrations of arachidonic acid. J Biol Chem 2001, 276(27):24743-24750.

56. Vucenik I, Ramakrishna G, Tantivejkul K, Anderson LM, Ramljak D: Inositol hexaphosphate (IP6) blocks proliferation of human breast cancer cells through a PKCdelta-dependent increase in p27Kip1 and decrease in retinoblastoma protein $(\mathrm{pRb})$ phosphorylation. Breast Cancer Res Treat 2005, 91(1):35-45.

57. Goodenough DA, Paul DL: Beyond the gap: functions of unpaired connexon channels. Nat Rev Mol Cell Biol 2003, 4(4):285-294.

58. Jiang JX, Gu S: Gap junction- and hemichannel-independent actions of connexins. Biochim Biophys Acta 2005, 1711(2):208-214.
59. Rodriguez-Sinovas A, Cabestrero A, Lopez D, Torre I, Morente M, Abellan A, Miro E, Ruiz-Meana M, Garcia-Dorado D: The modulatory effects of connexin 43 on cell death/survival beyond cell coupling. Prog Biophys Mol Biol 2007, 94(1-2):219-232.

60. Adam PJ, Boyd R, Tyson KL, Fletcher GC, Stamps A, Hudson L, Poyser HR, Redpath N, Griffiths M, Steers G, et al: Comprehensive proteomic analysis of breast cancer cell membranes reveals unique proteins with potential roles in clinical cancer. J Biol Chem 2003, 278(8):6482-6489.

61. Stains JP, Lecanda F, Towler DA, Civitelli R: Heterogeneous nuclear ribonucleoprotein $\mathrm{K}$ represses transcription from a cytosine/thymidinerich element in the osteocalcin promoter. Biochem J 2005, 385(Pt 2):613-623.

doi:10.1186/1471-2091-11-14

Cite this article as: Niger et al:: Interaction of connexin43 and protein kinase C-delta during FGF2 signaling. BMC Biochemistry 2010 11:14.

\section{Submit your next manuscript to BioMed Central and take full advantage of:}

- Convenient online submission

- Thorough peer review

- No space constraints or color figure charges

- Immediate publication on acceptance

- Inclusion in PubMed, CAS, Scopus and Google Scholar

- Research which is freely available for redistribution

Submit your manuscript at www.biomedcentral.com/submit
Biomed Central 